\title{
Strategies for Creating Engagement in Civil Engineering Students in Lecture Scenarios
}

Mr. Alan Chong, University of Toronto

Alan Chong is a Senior Lecturer with the Engineering Communication Program at the Univ. of Toronto, and is the communication coordinator for Civil Engineering, where he teaches a second year communication course, and administers a third year civil engineering portfolio. 


\section{Strategies for Creating Engagement in Civil Engineering Students in Lecture Scenarios}

\section{Introduction:}

Teaching a required engineering communication course to sophomore civil engineers, especially in a large classroom lecture setting, presents some significant challenges. Students face numerous roadblocks to engagement in lecture settings, including lecture/PowerPoint fatigue, physical fatigue from their demanding workloads, and other often more pressing engagements (such as upcoming exams or assignments). These challenges are exacerbated when the subject being taught is not particularly conducive to lecture-style teaching or perceived as less relevant to their disciplinary knowledge base, as with engineering communication. In such a scenario, strategies for creating engagement at the beginning of lectures are especially key to gaining and maintaining student attention, and creating the student buy-in that is key to their learning. Although this paper focuses on some challenges specific to an engineering communication classroom within the discipline of civil engineering, such strategies can be applied to almost all learning contexts in which greater engagement is desirable.

The discipline of civil engineering, however, is unique from other engineering disciplines in presenting numerous opportunities for engagement with cultural touchstones relevant to students of all levels. The general population engages daily with the products of civil engineering by using infrastructure, such as roads, buildings, and water systems. Our connection to these artifacts of civil engineering are thus reflected in cultural products such as popular music, film, and other media which hold cultural currency with students. This paper explores strategies for creating engagement for civil engineering students in lecture settings that take advantage of this strong connection between civil engineering and culture. Specifically, we examine three fields of cultural discourse - music, arts, and politics - then explain how these connections can be used in pre-lecture activities, and discuss the results of these strategies, as developed and trialled during a single semester sophomore course on Engineering Communication in civil engineering.

\section{Context:}

In fact, two problems are addressed by the strategies outlined in this paper: the first is a practical one emerging from university scheduling. At the University of Toronto, classes start 10 minutes after the hour and end on the hour, with a 10 minute break allotted for students to move between classes. Students try to take as much advantage of the 10 minute break as possible, meaning that they often are seated late, taking even more time to settle after they are seated. Motivating students to arrive early and become attentive quickly can sometimes be a challenge in this context, wasting valuable class time.

Secondly, as mentioned above, teaching communication to engineers presents its own challenges. The topic is not particularly compelling for the majority of students, many of whom have come to engineering to avoid performing writing or communication tasks. Nor is it typically seen as an 
essential skill for sophomore students, most of whom have yet to enter the industry in any meaningful way, and therefore, yet to experience for themselves how pivotal good communication skills can be to their jobs and to their career advancement. Keeping the audience attentive for a 50 minute lecture on communication concepts can often be a difficult task. Furthermore, engineering students are often suspicious of instructors who are not themselves engineers, and most technical communication instructors are not. Developing trust and respect between students and instructors in this context can be important to student buy-in and engagement with the course concepts.

One strategy for addressing this concern within our second year Engineering Communication course for civil engineering students has been to tie all written assignments to their technical courses. The two written assignments and one oral presentation are integrated with either an Introduction to Civl Engineering or an Engineering Ecology course, forcing students to apply principles from both technical and communication courses in their documents.

This paper, however, explores the attempt to address these challenges in another manner: by taking advantage of the time between classes to engage in activities that play with civil engineering's cultural resonances. Instead of starting 10 minutes after the hour, the class would begin with an activity, short film clip, or discussion (approximately 5 minutes after the hour), often culminating in a competition for a small, inconsequential prize. Some, such as Neil Postman in Amusing Ourselves to Death [1], might categorize these strategies as "edutainment," a derogatory term used to encompass the conflation of entertainment and education. These critics argue that "edutainment" achieves neither, because the two are mutual exclusive. While the debate on the effectiveness of educating through entertainment remains an important pedagogical question, it should be noted that the approach described in this paper does not combine entertainment and education. Rather, it entertains at the beginning of class to build rapport between students, instructors, and ultimately to create an audience conducive to being educated on a specific topic. These activities were designed to get students in the mood to engage, as a way to settle the class to make them more receptive to lecture style instruction on engineering communication, and to build a strong rapport between instructor and class, built on mutual engagement with the discipline.

\section{Civil Engineering and Popular Music:}

The first strategy involved a game called Civil Engineering Themed Musical Trivia, in which students compete within the lecture classroom to identify the title and artist for songs with either a titular or lyrical connection to civil engineering. Works and acts of civil engineering, unlike those of other engineering disciplines, have the advantage of being frequent topics of popular music. As to be demonstrated in the presentation at the conference, the activity was structured in the following manner:

1. A slide with a related visual would be put up on screen, with a field of civil engineering in the title. See Figure One, below. 


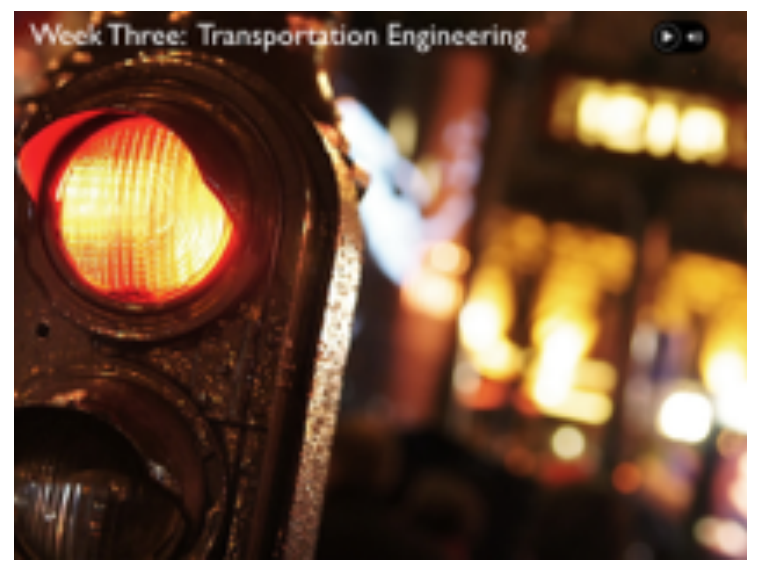

Figure 1: Clue for DJ Tiesto's Red Lights

2. The song would be played - sometimes from the start, but sometimes a more easily identifiable portion - over the AV system.

3. Students were asked to identify (A) the song title and, importantly, (B) the artist, and announce their answer as soon as they had a guess.

4. The winner - first to identify both elements - was awarded a small prize (such as a chocolate bar).

At the beginning of the year, we started the first class by playing Miley Cyrus's Wrecking Ball, a song that reached the \#1 position in Billboard's Top 100 list shortly after its premiere, and stayed on the charts for more than 16 weeks. Because the song was so ubiquitous at the time, almost all of the students were familiar with it. To start, though, we made no reference to the game itself, instead using Wrecking Ball as the prototypical example of a civil engineering themed song after the fact. Although connecting the song to the discipline required conflating a metaphorical and literal reading of the song's "wrecking ball," the song also allowed students to easily understand the nature of the activity, and to become quickly engaged with it.

The largest challenge in developing this activity involved finding the right songs: the class would, as a whole, need to be familiar enough with the song and its artist to be able to identify its connection to civil engineering. Table One - which lists the songs used for the activity over the course of the year, the relevant fields of civil engineering, and the time needed to identify the song - captures the nature of this challenge. Some songs were almost instantly identified; others, perhaps more famous or with very strong civil engineering connections, took much longer to identify because they were not nearly as current. Both types of songs, however, were necessary to keep students engaged in the activity: the class needed to both be given songs within their cultural milieu, which they could recognize quickly, and to be challenged by "classic" songs outside their immediate frame of reference. In other words, if the game was too easy, it would cease being enjoyable. 
Table One: Songs Used for Civil Engineering Themed Musical Trivia, Identified Civil Engineering Fields, Approx. Time for Identification

\begin{tabular}{|l|l|r|l|l|}
\multicolumn{1}{|c}{ Artist } & \multicolumn{1}{|c}{ Song Title } & Released & \multicolumn{1}{c|}{ Field } & Time to ID \\
\hline Miley Cyrus & Wrecking Ball & 2013 & Construction & n/a \\
\hline $\begin{array}{l}\text { Simon \& } \\
\text { Garfunkel }\end{array}$ & $\begin{array}{l}\text { Bridge over Troubled } \\
\text { Water }\end{array}$ & 1970 & Structural & $\sim 0: 30$ \\
\hline DJ Tiesto & Red Lights & 2014 & Transportation & $\sim 0: 10$ \\
\hline Maroon Five & Maps & 2014 & $\begin{array}{l}\text { Transportation, } \\
\text { Municipal }\end{array}$ & $\sim 0.10$ \\
\hline Demi Levato & Skyscraper & 2011 & Construction, Structural & $\sim 0.05$ \\
\hline Tragically Hip & New Orleans is Sinking & 1989 & Municipal, Water & $\sim 0: 10$ \\
\hline $\begin{array}{l}\text { Red Hot Chili } \\
\text { Peppers }\end{array}$ & Under the Bridge & 1991 & Structural & $\sim 0: 40$ \\
\hline Joni Mitchell & Big Yellow Taxi & 1970 & $\begin{array}{l}\text { Transportation, } \\
\text { Construction }\end{array}$ & $\sim 0: 50$ \\
\hline Tom Cochrane & Life is a Highway & 1992 & Transportation & $\sim 0: 40$ \\
\hline U2 & Where the Streets Have & 1987 & Municipal & $\sim 0: 50$ \\
\hline & No Name & & & \\
\hline
\end{tabular}

These results confirm our hypothesis that as a class, the students are relatively well versed in contemporary music, but less familiar with songs released prior to 2010. The single aberration from this trend, New Orleans is Sinking, which was identified very quickly despite the fact that it was released in the $80 \mathrm{~s}$, is a national touchstone. Other interesting insights included:

- Only 2 of nearly 100 students reported recognizing Simon and Garfunkel's Bridge Over Troubled Water, even minutes into the song. In fact, few students admitted to even being familiar with the song.

- Songs that had been covered and re-released were often recognized, but students could not identify the original artist. For example, Life is a Highway was associated with Rascal Flatts, and Big Yellow Taxi with multiple artists but not with Joni Mitchell (in fact, the closest students got was John Mitchell).

- Even songs considered to be cultural touchstones by the instructor may not have been familiar with the students. U2's Where the Streets Have No Name, for example, still took almost a minute for students to identify, despite its highly recognizable beginning.

There exist many, many songs with lyrical and titular connections to the civil engineering discipline. However, selection is pivotal to the success of this game in building engagement: 
songs that seem obscure to instructors, with the exception of very current songs, would probably be unrecognizable to most students.

More than anything else, however, this game, from the perspective of the instructor, helped focus student attention and develop engagement. Students were enthusiastically silent prior to the start of the game, and shouted out excitedly when they had the right answer (or at least felt they had the right answer). Adding a competitive aspect to the game, even though the prize was small, helped to further motivate students to focus and pay attention. Furthermore, students were quick to transfer their attentions from the game to the lecture content: it was a method for focalizing their attention on the lecturer, and relatively simple to turn their attention to the material immediately after. Most importantly, however, the activity helped build a collegial, fun, and civil engineering focused environment in the lecture room at the beginning of the class. And despite the fact that the instructor was not a civil engineer, this activity demonstrated his personal engagement with the discipline, and helped contribute to a good rapport with the students.

\section{Intersections of Civil Engineering and Art:}

Secondly, we also explored how clips from new and old multimedia, such as A Short History of the High-rise or the films and photography of Edward Burtynsky, can be introduced prior to lecture to get students thinking about important engineering concepts such as sustainability. Since one of the assignments for this communication course was tied to their technical course on Engineering Ecology, which asked students to identify problems with urban sustainability in a variety of cities and propose solutions, these cultural pieces were easily connected to the curriculum.

A Short History of the High-rise - a collaboration between the New York Times and the National Film Board of Canada by Katerina Cizek — is an experimental, award winning interactive documentary outlining the history of vertical living around the world [2]. The documentary allows viewers to sit back and watch a narrated history, told in rhyming couplets and narrated by Leslie Feist, or to interact with material on high-rise living from the archives of the New York Times. Viewers could choose to read or listen to material that was not part of the documentary proper, but that was built into the website for the project, and even, in the last component, contribute their images to the fourth part of the film. Students were introduced to the first few minutes of the documentary prior to class, shown the interactive components, then shown the beginning of the next part in the following class, and encouraged to explore more of the documentary in their own time.

Other source material included the work of Edward Burtynsky [3-4], a large format photographer whose photos of landscapes profoundly changed by industry or human use, such as tailings dams, quarries, or large scale projects, arrive with strong visual impact, especially when presented on a large screen similar to the size of his actual photos. His work and process have also been turned into the documentaries Manufactured Landscapes and Watermark by Jennifer Baichwal. In this instance, a slide show of his best photos or the trailer for the documentary was 
shown prior to class, with little set up commentary providing the necessary context. This year, we had the good fortune of having Edward Burtynsky's work on display in a nearby gallery, and could also direct students to see his actual pieces.

Both of these cultural products compelled students to watch and focused their attention on the screen. Students settled down almost immediately after the clips were loaded, and were quick to turn their attention to lecture material when they ended. Importantly, the content of these pieces allowed for strong, topical transitions to their assignments and were followed up by discussions of engineering communication strategies using examples around the issues of urban density and sustainability.

\section{Politics:}

Finally, we tried to use local, municipal political issues (in a non-partisan way) to demonstrate the significance of their chosen discipline to their daily lives. In 2014, we were fortunate enough to have a highly contested, well covered mayoral race in which transportation and urban planning issues were extremely prominent. Each candidate's platform focused on their transportation plan, and debates often circulated around issues of transit planning, funding, and and urban versus suburban divide. Strategies for using the mayoral race included: (A) showing clips from mayoral debates, especially the heated moments around their policies on transportation, or recent television interviews, (B) recent newspaper clippings highlighting key issues, or (C) literature from the campaigns, such as transit plans. With textual documents, commentary had to be provided to focus student attention, often on the rhetoric of the candidates. Similarly, clips from debates or interviews could be examined for rhetorical strategies, language, and tone.

While these forays into political speech around civil engineering projects produced the closest connections to engineering communication concepts, they were also the least successful in focusing the class on the lecture at hand. Students watched and listened carefully, though not as closely as with the music or artistic pieces, but were more engaged and less likely to be attentive because they wanted to discus their views on transit policies and the mayoral race. It was also challenging to remain non-partisan. However, the degree of their excitement around these political manifestations of civil engineering practice did indicate a level of engagement that we could make use of, at least in turning their attention to their own reporting on transit or urban issues.

\section{Impact:}

So far, all of the evidence for the efficacy of the strategies have been subjective, and taken from the instructor perspective on the course. Student opinions on these strategies were measured in two ways, first via course evaluations and second, via a brief survey conducted several months after the end of the course. 
Via course evaluations, we have promising but inconclusive data on the efficacy of such techniques. Compared to the prior year, in which no such strategies were used, several key improvements were made. When students were asked to assess whether the instructor helped create an atmosphere conducive to learning on a five point Lichert scale (1-not at all, 2 moderately, 3-somewhat, 4-mostly, 5-a great deal), they returned a mean score of 4.5, a 0.5 improvement from the previous year. When students were asked to assess the overall quality of the instructor on a five point Lichert scale, they returned a mean score of 4.5 (1-poor, 2 - fair, 3good, 4-very good, 5-excellent), a 0.4 improvement from the previous year. Several free form student comments identified the atmosphere created in the class as important to their learning, even without probing from the questionnaire:

"[The professor] kept the class lively with a good sense of humour, especially during the civil engineering themed trivia sessions."

"[I am hopeful] that we can continue to play the civ related songs, and testing us at the beginning of class."

"The professor was enthusiastic about course materials and tried to relate materials to current or recent events which helped."

The short survey asked only three questions, two multiple choice and one paragraph form, and was more:

(1) Did they enjoy the pre-lecture activities?

(2) Did the pre-lecture activities contribute to their engagement with the course?

(3) Please comment on the perceived impact of these activities on your experience of the course.

(What did you like/dislike about these activities, how did it impact your attitude towards the course/instructor etc.)

Provided responses to the first two questions were based on a 5 point Lichert scale (1-not at all, 2-moderately, 3-somewhat, 4-significantly, 5-a great deal). From a class of approx. 100, we received 23 responses to the survey.

The response to question (1) reinforces the instructor perception of the activity's reception. The mean was 4.6, between significantly and a great deal, with a median of 5. Only two students reported somewhat enjoying the activity, though this result may be skewed by the fact that the respondents were self selecting. For question (2), the response was less positive (mean 4.1, median 4), but still indicates that the activities helped engagement significantly. More students reported being only somewhat engaged; still, none of the respondents fell into the lowest two categories. More interesting, however, are the paragraph responses from the students, which reinforce the objectives of the strategy. One characteristic response was that "it made the class more engaging and fun." Others noted that the activity "gave me a reason to show up to lecture." Yet other student responses help to clarify the impact of the activity. The following three responses reiterate a similar experience: 
"Because of the pre-lecture activities, I found once the lecture actually started, I was ready and engaged to listen."

"It was a fun way to start the class. Eased into things and made a more relaxed environment. Much better than just going straight into course material."

"I felt that the activities were a fun way to engage the class before starting into the lecture material. It made the instructor more approachable."

These comments speak to the importance of "breaking the ice," not only at the beginning of the year, but with each lecture. Even the one exception to the responses, who did not see an impact on their "view of the course materials" acknowledged that "it did uplift the mood of the class, however."

\section{Conclusion:}

While this is by no means a comprehensive analysis of the efficacy of these methods, it does indicate that we can use the oft wasted time between classes productively. It can be used to develop connections to relevant course materials, or just to build a little bit of spirit for the civil engineering class. For the instructor in an engineering communication class, the methods were also pivotal in demonstrating his own engagement with civil engineering topics, and in developing a strong rapport with the students. Our results indicate that these strategies, which take merely 3-5 minutes and can be conducted before the start of lecture, do help students to focus their attention and engage with the material being presented.

[1] Neil Postman. Amusing Ourselves to Death. Public Discourse in the Age of Show Business. New York: Penguin, 2005.

[2] Kristina Cizek. "A Short History of the High Rise," National Film Board of Canada and The New York Times, 2013. http://www.nytimes.com/projects/2013/high-rise/ Last accessed 2015-01-29

[3] Edward Burtynsky. "Projects," 2015. http://www.edwardburtynsky.com/site_contents/ Photographs/introPhotographs.html Last accessed 2015-01-29

[4] Edward Burtynsky and Jennifer Baichwal. "Watermark trailer" Mongrel Media, 2013. https://www.youtube.com/watch?v=QpvarPeJpkM Last accessed 2015-01-29 